Technical Report No. 32-326

\title{
The Bearing Capacity of Simulated Lunar Surfaces in Vacuum
}

\author{
E. C. Bernett \\ R. F. Scott \\ L. D. Jaffe \\ E. P. Frink \\ H. E. Martens
}

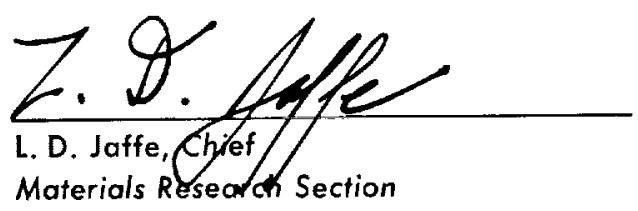

JET PROPULSION LABORATORY

CALIFORNIA INSTITUTE OF TECHNOLOGY

PASADENA, CALIFORNIA

August 15, 1963 


\author{
Copyright (C) 1963 \\ Jet Propulsion Laboratory \\ California Instifute of Technology \\ Prepared Under Contract No. NAS 7-100
}

National Aeronautics \& Space Administration 


\section{CONTENTS}

I. Introduction . . . . . . . . . . . . . . . . . 1

II. Materials and Sample Preparation . . . . . . . . . . . . 2

III. Test Equipment and Procedure . . . . . . . . . . . . . 5

IV. Test Results . . . . . . . . . . . . . . . . . . . . . . . . . 7

V. Discussion . . . . . . . . . . . . . . . . . . . . . 9

VI. Conclusions . . . . . . . . . . . . . . . . . . . . . 12

References . . . . . . . . . . . . . . . . . 12

Table 1. Particle size distribution; basalt powder, 6/61 . . . . . 2

\section{FIGURES}

1. Flow diagram for crushing of basalt (Lot $6 / 61)$. . . . . . . . . . 3

2. Particle size distribution of basalt powder . . . . . . . . . . . . . . 4

3. Apparatus for measuring bearing capacity of rock powder . . . . . . 5

4. Mass bearing stress vs penetration depth of basalt powder . . . . . 5

5. Bearing capacity of basalt powder in vacuum and in air $\quad$. . . . . . . . 7

6. Range of bearing capacity of basalt powder, for small probes . . . . 8

7. Mass bearing capacity vs packing density of basalt powder, for small probes. . . . . . . . . . . . . . . . . . . . . . 9 
JPL TECHNICAL REPORT NO. 32.326

\section{ACKNOWLEDGMENT}

R. F. Scott, co-author of this report is an Associate Professor of Civil Engineering, California Institute of Technology. 


\begin{abstract}
The static bearing capacity of a granular material consisting of dry, crushed olivine basalt was determined in air and in a $10^{-6} \mathrm{~mm} \mathrm{Hg}$ vacuum by means of cylindrical probes with a range of diameters. Samples with various particle size distributions (all below 35 mesh) were used for these tests. It was found that the packing density of these granular materials was the factor which had the greatest effect on the bearing capacity. The minimum bearing capacity of a loosely packed sample with a density of $1.25 \mathrm{~g} / \mathrm{cm}^{3}$ was about $0.1 \mathrm{~kg} / \mathrm{cm}^{2}$. The maximum bearing capacity of a densely packed sample with density of $2.1 \mathrm{~g} / \mathrm{cm}^{3}$ was about $7 \mathrm{~kg} / \mathrm{cm}^{2}$. The effects of vacuum were insignificant compared with the effect of packing density. Direct shear tests indicated the cohesion in a few densely packed samples to be $1-2 \times 10^{4}$ dynes $/ \mathrm{cm}^{2}$. For the small probes used, the cohesion was estimated to contribute 85 to $95 \%$ of the observed bearing capacity for the densely packed samples, but much less for the loosely packed samples.
\end{abstract}

\title{
I. INTRODUCTION
}

There is a great deal of design work in progress on the equipment and instrumentation required for the lunar exploration program. Precise information with regard to the nature and properties of the lunar surface would be very helpful to those involved in this work. Past studies by optical and radio astronomy have indicated that large portions of the Moon's surface are composed of low density material, probably in powder or porous form (Ref. 1). It is therefore desirable to determine if proper- ties of granular or porous materials are markedly different in high vacuum than in air. Studies have been carried out on powdered minerals in vacuum; the properties evaluated include resistance to dynamic penetration (Ref. 2, 3), thermal conductivity (Ref. 4), and land locomotion values (Ref. 5). In the present work the static bearing capacity of rock powder was evaluated in air and in high vacuum. 


\section{MATERIALS AND SAMPLE PREPARATION}

It was desired to measure the bearing capacity of each lot of powder over a wide range of packing density. Data at the lowest densities were of particular interest. To obtain minimum packing densities, extreme care was taken during the loading of the powders into the sample holder. A small scoop was used for this purpose and each scoopful was gently placed on the surface of the material previously added. Samples with packing densities as low as $1.25 \mathrm{~g} / \mathrm{cm}^{3}$ were thus obtained. The high density samples were prepared by filling the container with powder and then tapping it on a solid surface. With care in the tapping procedure, spalling of the surface was avoided and packing densities as high as $2.29 \mathrm{~g} / \mathrm{cm}^{3}$ were obtained.

The simulated lunar surface materials used in this bearing capacity study were prepared from unweathered olivine basalt collected from Pisgah Crater, San Bernar- dino County, California. A detailed mineralogical description of this volcanic rock is given in Ref. 2. The rough breakdown, crushing, pulverizing, and sizing operations were carried out as shown in the flow diagram (Fig. 1). Six lots of granular material were obtained; two were well graded, with nominal mesh sizes of -35 and -150 , four were more uniformly sized, with nominal mesh sizes of $-35+48,-48+65,-65+100,-100$ +150 . A particle size distribution analysis was carried out on each lot; the results are shown in Table 1 and Fig. 2.

The rock powders were stored in covered containers and were dry except for moisture picked up from the air. Checks made during the program by drying selected samples showed the water content was always less than $0.1 \%$ by weight. The density of the solid particles was found to average $2.97 \mathrm{~g} / \mathrm{cm}^{3}$.

Table 1. Particle size distribution; basalt powder, batch $6 / 61$

\begin{tabular}{|c|c|c|c|c|c|c|c|}
\hline \multirow{2}{*}{\multicolumn{2}{|c|}{ Measured particle size }} & \multicolumn{6}{|c|}{ Nominal mesh size } \\
\hline & & \multirow{2}{*}{$\begin{array}{c}-35 \\
+48 \\
\%\end{array}$} & \multirow{2}{*}{$\begin{array}{c}-48 \\
+65 \\
\%\end{array}$} & \multirow{2}{*}{$\begin{array}{c}-65 \\
+100 \\
\%\end{array}$} & \multirow{2}{*}{$\begin{array}{c}-100 \\
+150 \\
\%\end{array}$} & \multirow[b]{2}{*}{$\begin{array}{c}-35 \\
\%\end{array}$} & \multirow[b]{2}{*}{$\begin{array}{c}-150 \\
\%\end{array}$} \\
\hline Mesh & Microns & & & & & & \\
\hline $\begin{array}{r}+28 \\
-28+35 \\
-35+48 \\
-48+65 \\
-65+100 \\
-100+150 \\
-150+200 \\
-200+270 \\
-270+325\end{array}$ & $\begin{array}{c}>590 \\
<590>420 \\
<420>297 \\
<297>210 \\
<210>149 \\
<149>105 \\
<105>74 \\
<74>53 \\
<53>44 \\
<44>35 \\
<35>25 \\
<25>12 \\
<12>7 \\
<7>3 \\
<3\end{array}$ & $\begin{array}{r}0.02 \\
0.94 \\
81.96 \\
16.00 \\
0.45 \\
0.02 \\
0.01 \\
0.01 \\
0.01 \\
0.02 \\
0.01 \\
0.05 \\
0.09 \\
0.05 \\
0\end{array}$ & $\begin{array}{l}0 \\
0.03 \\
0.83 \\
83.42 \\
14.57 \\
0.04 \\
0.03 \\
0.03 \\
0.02 \\
0.02 \\
0.01 \\
0.10 \\
0.24 \\
0.21 \\
0\end{array}$ & $\begin{array}{l}0 \\
0.03 \\
0.02 \\
0.93 \\
79.29 \\
18.25 \\
0.07 \\
0.01 \\
0.01 \\
0.01 \\
0.02 \\
0.10 \\
0.43 \\
0.20 \\
0\end{array}$ & $\begin{array}{l}0 \\
0.02 \\
0.02 \\
0.02 \\
0.63 \\
85.25 \\
12.46 \\
0.08 \\
0.04 \\
0.02 \\
0.02 \\
0.15 \\
0.44 \\
0.37 \\
0\end{array}$ & $\begin{array}{r}0.13 \\
0.13 \\
8.96 \\
12.75 \\
13.56 \\
11.99 \\
8.83 \\
9.92 \\
10.80 \\
7.98 \\
5.43 \\
4.57 \\
2.99 \\
1.13 \\
0\end{array}$ & \begin{tabular}{c}
\multicolumn{1}{c}{0} \\
0.01 \\
0.02 \\
0.02 \\
0.02 \\
0.91 \\
15.49 \\
20.73 \\
9.67 \\
14.88 \\
10.75 \\
13.39 \\
8.32 \\
5.69 \\
0
\end{tabular} \\
\hline $\begin{array}{l}\text { Note: Analysis use } \\
\text { Sizes below }\end{array}$ & $\begin{array}{l}\text { as on Ro-Tap } \\
\text { n mieromero }\end{array}$ & & & & & & \\
\hline
\end{tabular}




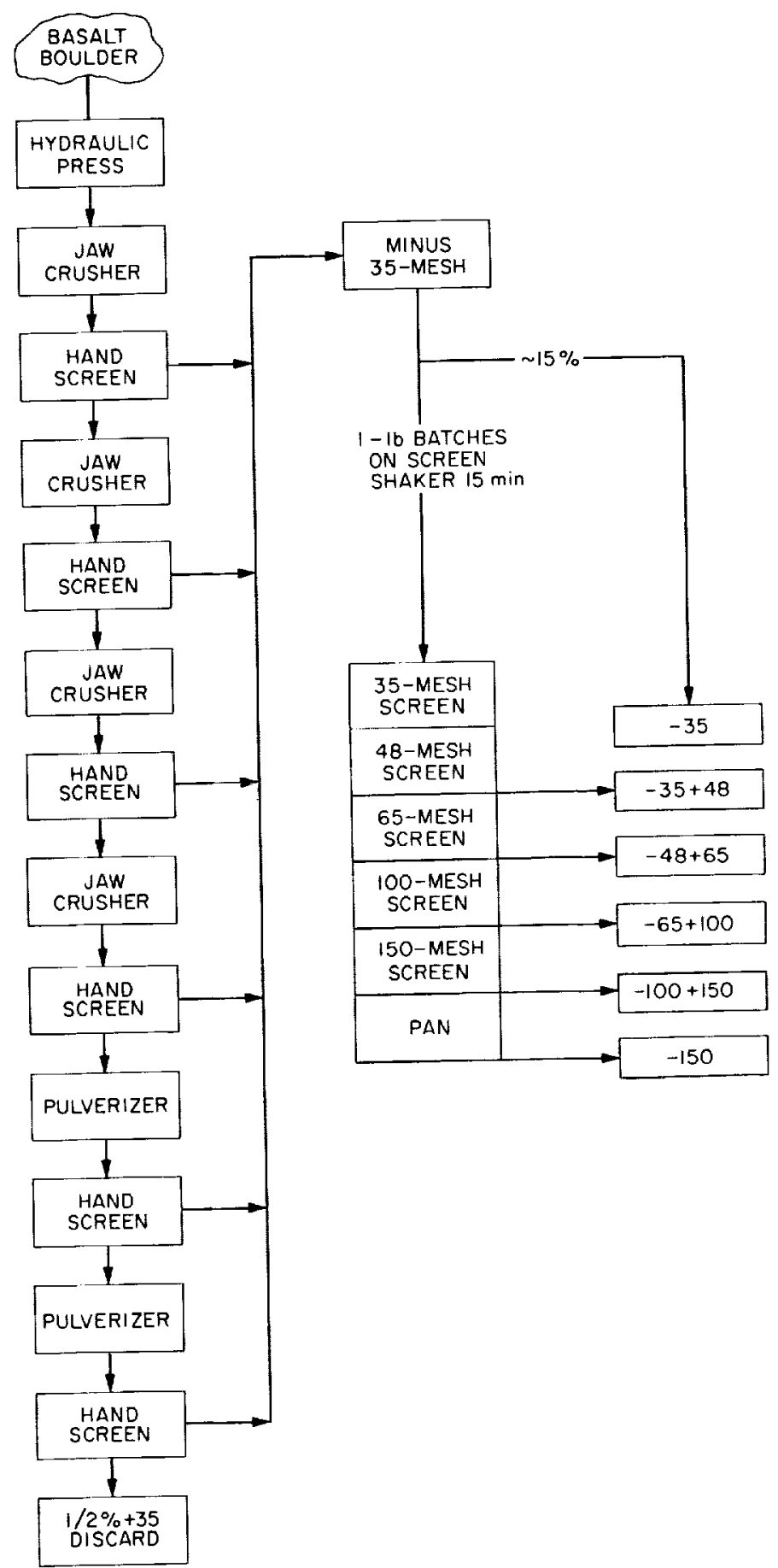

Fig. 1. Flow diagram for crushing of basalt (Lot 6/61) 
JPL TECHNICAL REPORT NO. 32-326

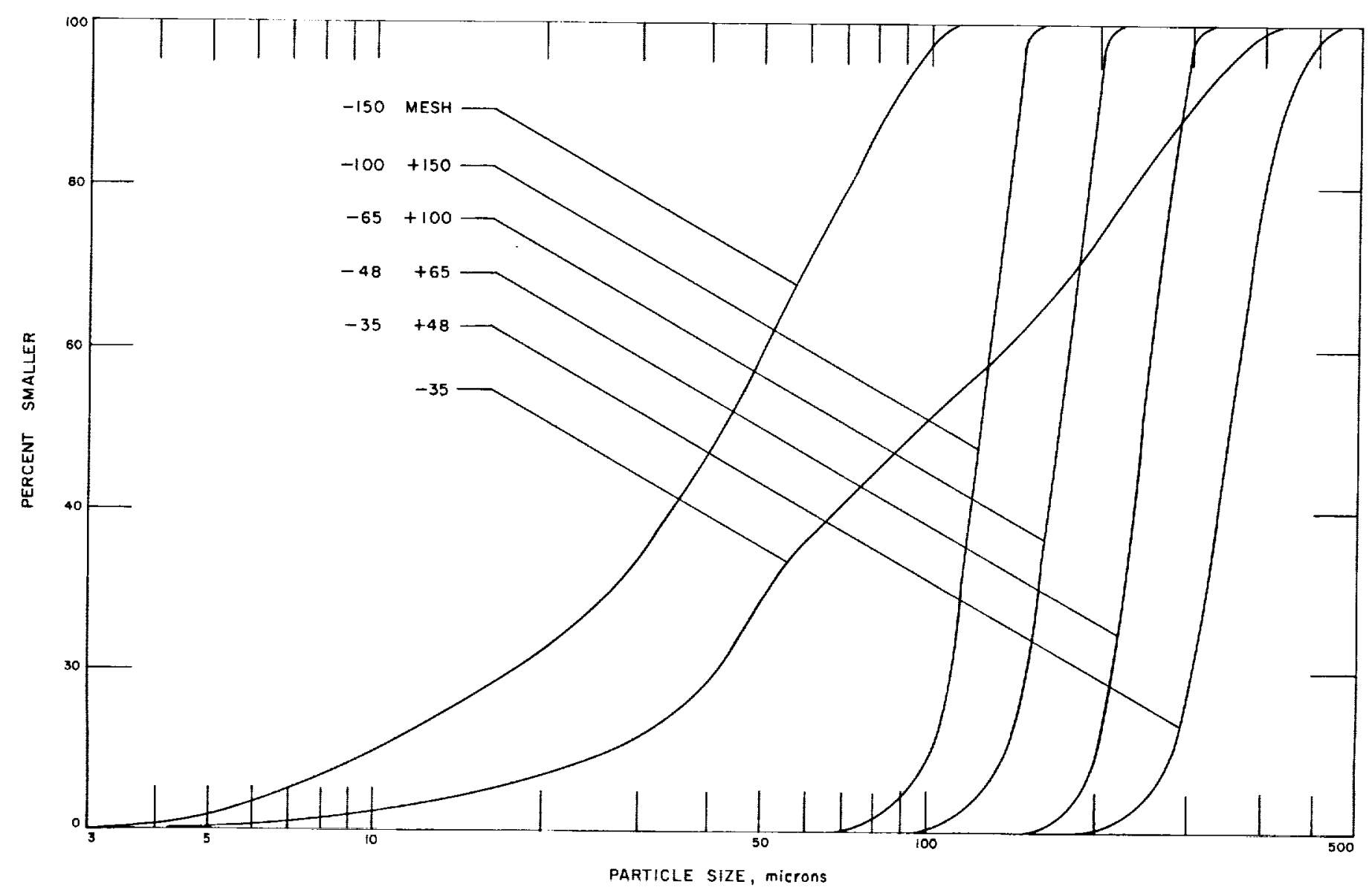

Fig. 2. Particle size distribution of basalt powder 


\section{TEST EQUIPMENT AND PROCEDURE}

The apparatus used for the bearing capacity measurements was a simple penetrometer (Fig. 3) using interchangeable, circular, flat-bottom probes of a range of diameters; such probes are commonly used in soil mechanics studies. A bushing on the probe stem constrained the probe base to remain horizontal so that soil displacements would take place symmetrically about the probe axis, in the absence of boundary effects. Lead-shot loading was used for convenience in adapting the unit for operation in vacuum; with this procedure the load was measured only at failure. The initial tests were made in air. Multiple measurements were made on every soil sample. Test locations were kept at least two probe diameters away from the container walls and the edges of the craters produced by previous tests; this allowed three to five tests to be made on the $23-\mathrm{cm}$ diameter surface of a sample.

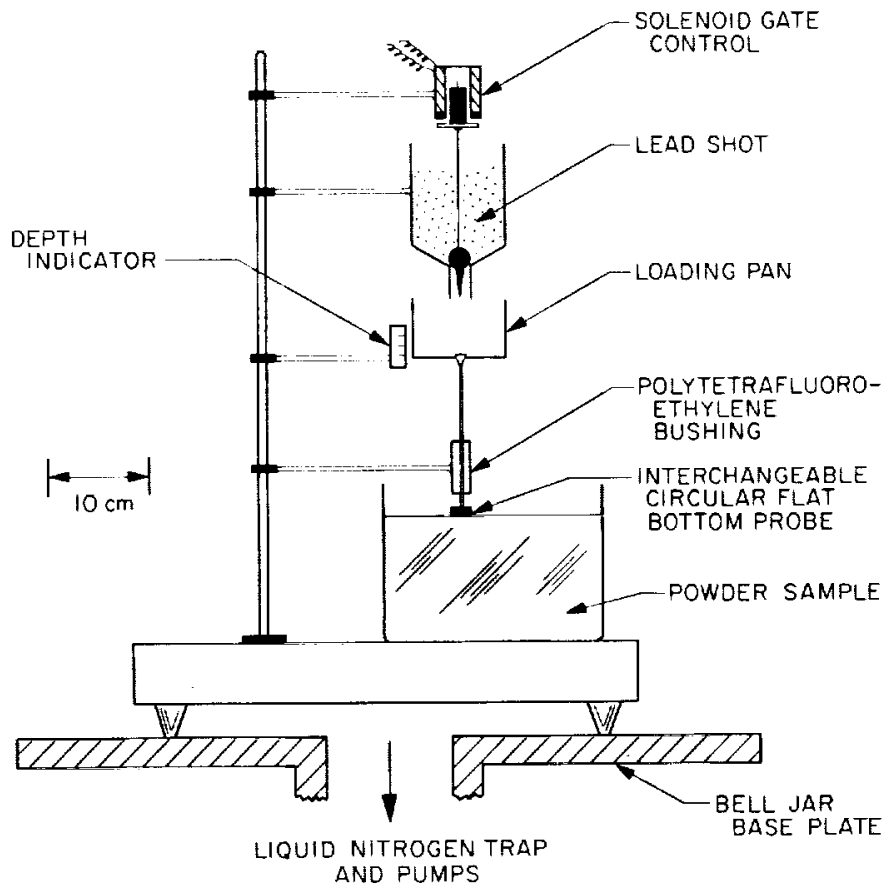

Fig. 3. Apparatus for measuring bearing capacity of rock powder (bell jar and vacuum lead-through not shown!

As might be expected from the known characteristics of soils in air, the load versus depth of penetration behavior (both in air and vacuum) was distinctly different for the loosely packed and the densely packed samples
(Fig. 4). For loosely packed material the penetration increased gradually as the load increased. There was relatively little soil movement visible except for caving of the walls as the probe penetrated below the surface. The mass per unit area at which the depth of penetration was equal to the probe diameter was taken as the mass bearing capacity. For densely packed material radial cracks formed about the probe as the load increased; however, the penetration was negligible until a critical load was reached at which there was sudden yielding. The probe would then sink to a depth of about $1 / 2$ to $1 \mathrm{D}$ and produce a cavity with more or less vertical walls. The mass per unit area corresponding to the yicld load was considered the mass bearing capacity.

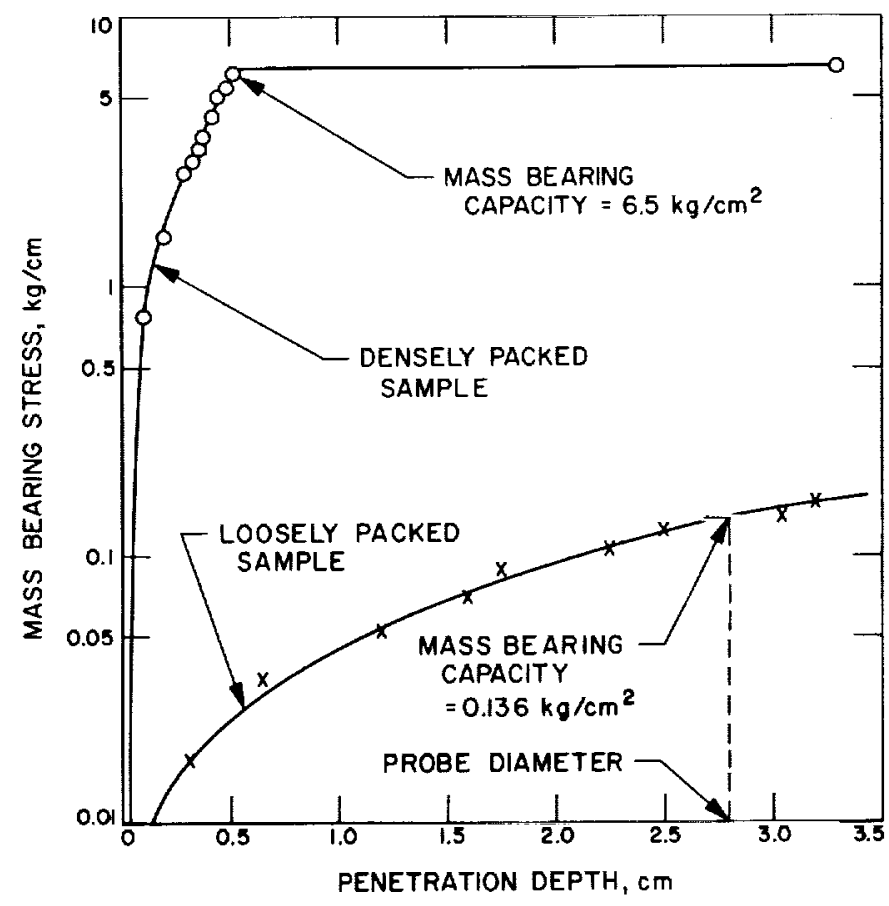

Fig. 4. Mass bearing stress vs penetration depth of basalt powder

The vacuum system consisted of a $45-\mathrm{cm}$ glass bell jar, 15-cfm mechanical pump, and a liquid-nitrogen-trapped oil diffusion pump (speed 800 liters $/ \mathrm{sec}$ at $10^{-4} \mathrm{~mm} \mathrm{Hg}$ ). The principal difficulty in determining the bearing capacities of the samples in vacuum was to avoid any disturbances of the packing near the surface during evacuation. Starting at atmospheric pressure, the jar could be evacu- 
ated to $10^{-5} \mathrm{~mm} \mathrm{Hg}$ in about $45 \mathrm{~min}$ at normal pumping rate. To prevent eruptions or other visible disturbances of the sample, however, the pumping speed was throttled to a point where approximately $6 \mathrm{hr}$ was required to evacuate the space above the sample to a pressure of $10^{-6} \mathrm{~mm} \mathrm{Hg}$. It should be noted that the subsequent repressurization of a sample could also cause a disturbance of the packing; therefore air had to be admitted slowly after testing. The time to change pressure from the $10^{-6} \mathrm{~mm} \mathrm{Hg}$ range to atmospheric was approximately $6 \mathrm{hr}$. To check packing disturbance during evacuation and repressurization, bearing capacity measurements were made in air both before and after a test in vacuum.

Each sample tested in a vacuum thus had spent six $\mathrm{hr}$ or more in the vacuum chamber, during which time the pressure in the space above the sample had been reduced from atmospheric to $10^{-6} \mathrm{~mm} \mathrm{Hg}$. Degassing tests on crushed samples of the same basalt have been reported (Ref. 2). These tests, made with a vacuum system of lower pumping speed than that used in the present work, indicate the vacuum attained was little affected by heating the material. As mentioned previously the rock powders picked up some moisture from the air (less than $0.1 \%$ ). To determine whether this had any effect on the bearing capacity as measured, one series of tests was run on material which had been held at $105^{\circ} \mathrm{C}$ for $24 \mathrm{hr}$.

The effects of longer vacuum exposure time were checked by making a measurement on a sample which had been held for $40 \mathrm{hr}$ in a vacuum which reached $2 \times 10^{-6} \mathrm{~mm} \mathrm{Hg}$.

To examine the effects of probe size, probes with 0.45 , 0.72 and $1.43 \mathrm{~cm}$ radii were used. At least two probe sizes were used for each sample. With dense soil the load required with the $1.43-\mathrm{cm}$ probe was beyond the capacity of the regular equipment. A few tests were run in air with equipment of greater capacity; this equipment was too large to fit into the vacuum bell jar.

Measurements of cohesion were made on a few samples with a standard soil mechanics direct-shear apparatus. 


\section{TEST RESULTS}

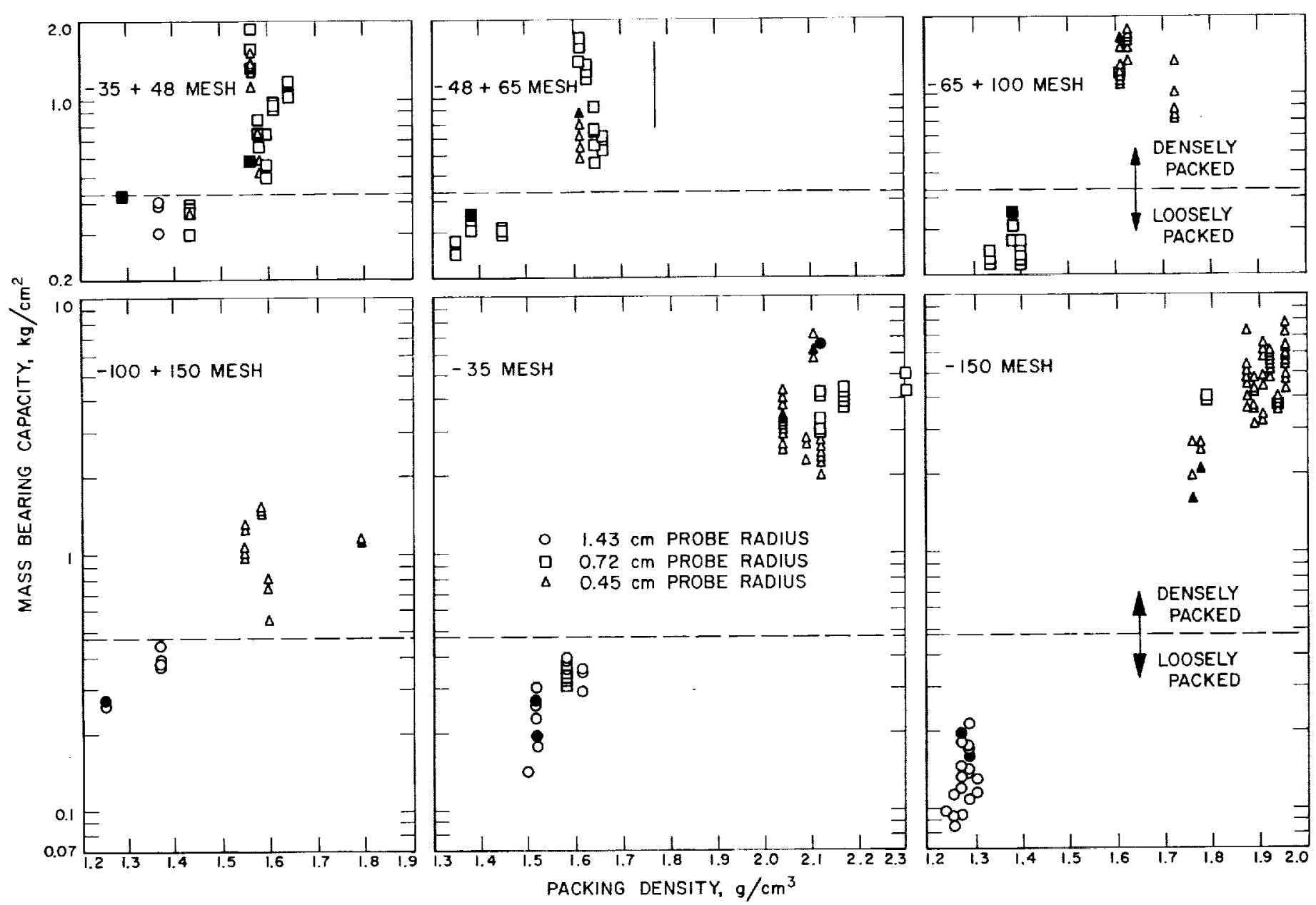

Fig. 5. Bearing capacity of basalt powder in vacuum and in air lopen symbols designate air tests and solid symbols vacuum tests)

The measured bearing capacities in air and vacuum are plotted in Fig. 5 against corresponding packing densities for each of the six lots of basalt; the probe sizes used are also indicated.

Figure 6 shows, for each nominal mesh size, the range of bearing capacities measured in air and the individual data points measured in vacuum. In the loosely packed condition the lowest mass bearing capacity measured in vacuum was $0.16 \mathrm{~kg} / \mathrm{cm}^{2}$ and in air was $0.085 \mathrm{~kg} / \mathrm{cm}^{2}$. In the densely packed condition the highest value was $6.2 \mathrm{~kg} / \mathrm{cm}^{2}$ in vacuum and $7.1 \mathrm{~kg} / \mathrm{cm}^{2}$ in air.
The bearing capacity measurements made in air on the material which had been heated to remove residual moisture were not significantly different and are included in the Fig. 5 air data.

The direct shear tests on the -35 mesh material gave angles of internal friction of $44 \mathrm{deg}$ for a densely packed $\left(2.0 \mathrm{~g} / \mathrm{cm}^{3}\right)$ sample and $26 \mathrm{deg}$ for a loosely packed $(1.4$ $\mathrm{g} / \mathrm{cm}^{3}$ ) sample. Using the same apparatus, with very low normal loads giving pressures of less than $3 \times 10^{4}$ dynes/ $\mathrm{cm}^{2}$ on the failure surface, a cohesion of $1.4 \times 10^{4}$ dynes $/ \mathrm{cm}^{2}$ was measured on a densely packed sample of 
the -35 mesh material and $2.1 \times 10^{4}$ dynes $/ \mathrm{cm}^{2}$ for a densely packed sample of $-100+150$ mesh material. These measurements were made on material taken from the surface of samples on which penetration tests were made.

The long-time vacuum exposure test on a densely packed -35 mesh sample showed that very much less cracking took place at the sample surface on penetration, and that, as the probe was pushed further below the surface, the soil at the edge of the penetration hole fell into an angle of repose without sustaining a vertical wall. This is in contrast to the tests in air and after six hr in vacuum in which the probe left a cylindrical hole with vertical wall, and a vertical trench $10 \mathrm{~cm}$ deep could be excavated without failure of the vertical wall.

Attempts to excavate a vertical trench in a loosely packed sample were unsuccessful, indicating that in this condition the soil exhibited negligible cohesion.

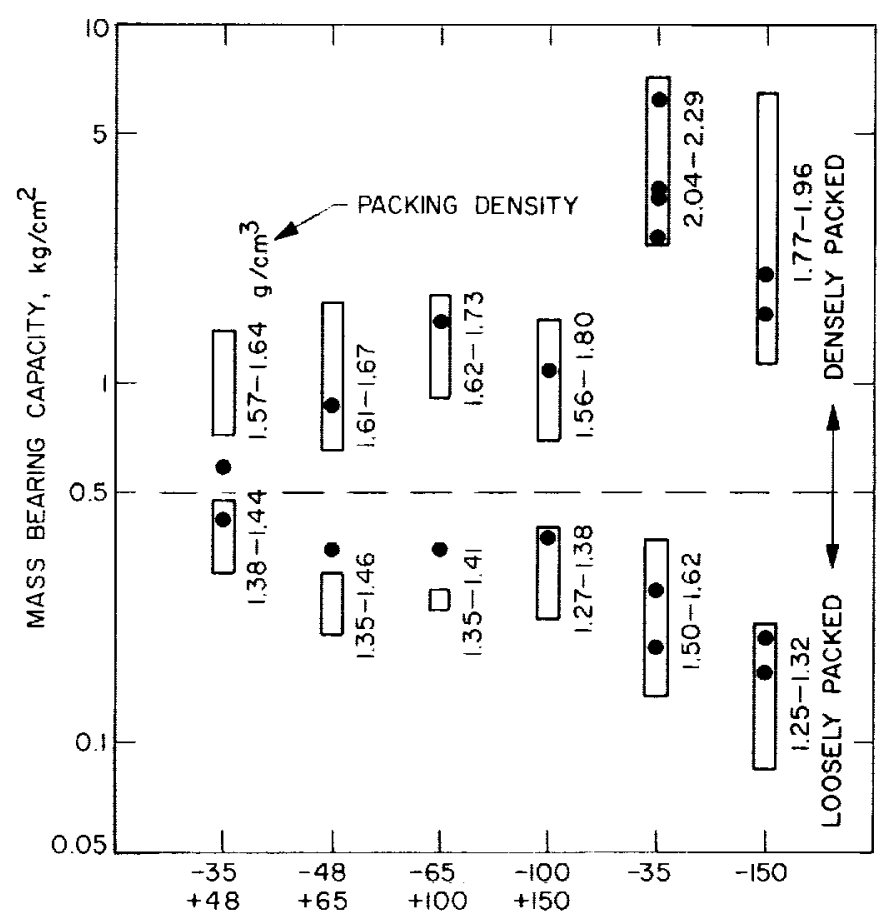

NOMINAL MESH SIZE OF TESTED MATERIAL

Fig. 6. Range of bearing capacity of basalt powder, for small probes lbar length indicates the range in air; solid circles show individual data points in vacuum) 


\section{DISCUSSION}

As the samples used in this study were prepared by hand, there were differences in structure and packing density from sample to sample among those intended to have similar states of packing. Undoubtedly, there were some localized differences on the surface and within each individual sample as well. The differences caused some scatter in the measured bearing capacities; nevertheless, the tests showed clearly that the bearing capacity of the rock powders was the same in a vacuum, of the level and for the times employed, as in air under the test conditions. Figure 6 shows that the vacuum results fall within the range observed in air tests.

The factor which had the greatest effect on the bearing capacity was the packing density. The bearing capacities of the crushed basalts varied directly with the packing density. The greatest range of densities and corresponding bearing capacities (Fig. 5) was obtained on the materials with the broad range of particle sizes, i.e., the -35 and -150 mesh. As would be expected from the geometry of particle packing, much higher densities could be obtained with these broad particle size distributions than with the lots in which most of the particles fell within a narrow range of sizes.

In Fig. 7 the mass bearing capacities measured for all lots are plotted versus packing density. Averages are shown for air tests and individual data points for vacuum tests. It is clear that most of the results fall within a relatively narrow scatter band, regardless of particle size distribution or atmospheric pressure, and represent an approximately linear relation between the logarithm of bearing capacity and the packing density. The bearing capacities for the -35 mesh material fall below those for the other particle sizes.

The approximate expression for the bearing load, $P$, of a circular plate of radius, $R$, at a depth, $D$, below the surface of a soil of unit weight, $\gamma=\rho g$, and cohesion, $c$, is

$$
P=\pi R^{2}\left[c N_{c}+\gamma D N_{q}+\gamma R N_{\gamma}\right]
$$

in which, if the units are chosen compatibly, $N_{c}, N_{q}$, and $N_{\gamma}$ are dimensionless parameters, applying to a circular footing and depending only on the angle of internal friction of the soil.

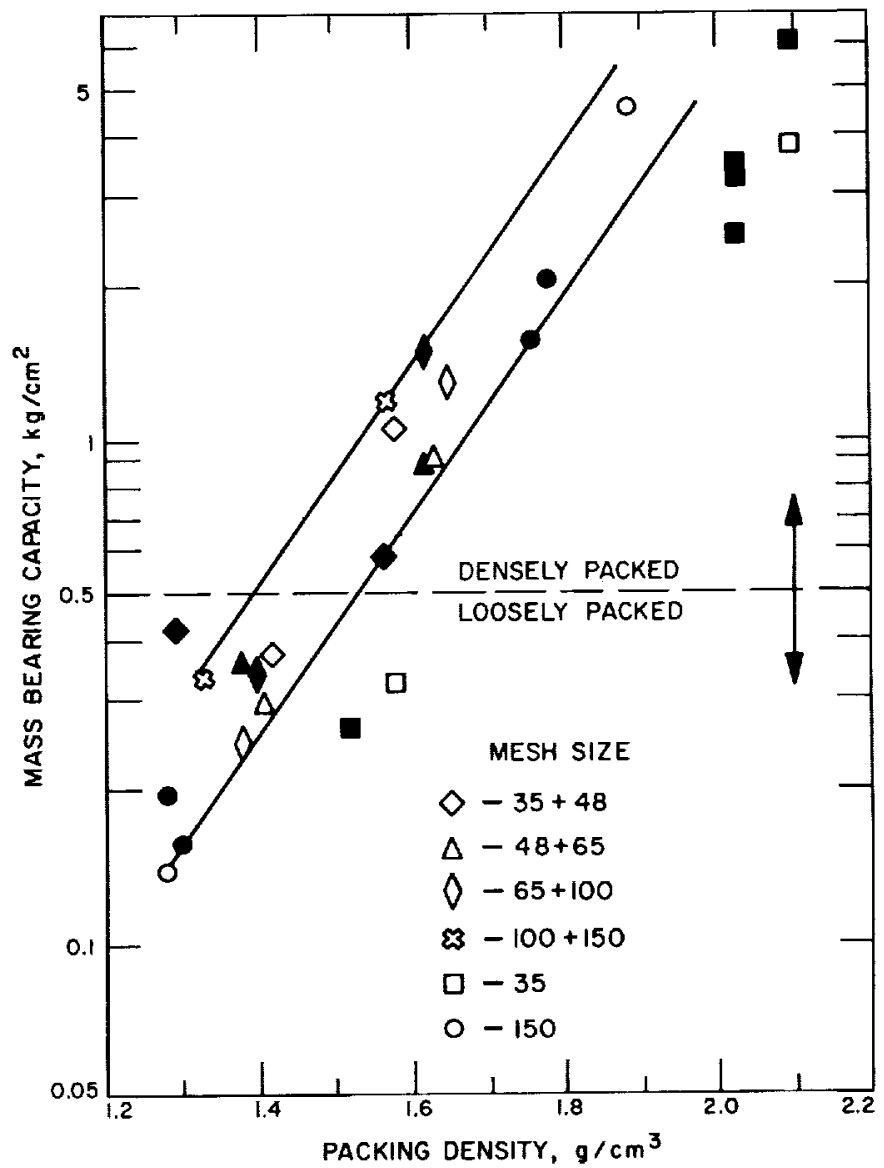

Fig. 7. Mass bearing capacity vs packing density of basalt powder, for small probes (solid symbols indicate individual data points in vacuum; air test points are averages)

In the tests on the densely packed samples, the depth at which "yielding" took place was relatively small. Thus $D \simeq 0$, and $\mathrm{Eq}_{1}(1)$ becomes

$$
P=\pi R^{2}\left[c N_{c}+{ }_{\gamma} R N_{\gamma}\right]=\pi R^{2}\left[c N_{c}+\rho g R N_{\gamma}\right]
$$

The maximum bearing capacity, $p$, is

$$
p=\frac{P}{\pi R^{2}}=c N_{c}+\rho g R N_{\gamma}
$$

The gravitational acceleration, g, will be different on the Moon and Earth. We can define the mass bearing capacity $p_{m}=p / g$ and then write $\mathrm{Eq}(3)$ as 


$$
p_{m}=\frac{c N_{c}}{g}+{ }_{\rho} R N_{\gamma}
$$

If the results of the penetration tests on densely packed samples are extrapolated to give bearing capacities of larger footings, the contribution due to cohesion remains constant, whereas that arising from the friction term including $N_{\gamma}$ in Eq (3) and (4) increases linearly with the width of the footing. To examine the proportions of the bearing capacity attributable to the different items, $\mathrm{Eq}$ (3) and (4) may be rewritten in the forms

$$
\frac{p}{\rho g R}=\frac{c}{\rho g R} N_{c}+N_{\gamma}
$$

or

$$
\frac{p_{m}}{\rho R}=\frac{c}{\rho g R} N_{c}+N_{\gamma}
$$

in which the left-hand sides are dimensionless bearing capacities, and $c / \rho g R$ is a dimensionless factor expressing a relation among the cohesion and density of the soil, the size of the footing, and gravity. For densely packed samples of the -35 mesh material $\left(c=1.4 \times 10^{4}\right.$ dynes $\left./ \mathrm{cm}^{2}\right)$, $c / \rho g R$ has values of 15 and 9.4 for the small $(0.45-\mathrm{cm}$ radius) and large $(0.72 \mathrm{~cm}$-radius) probes respectively. For densely packed samples of the $-100+150$ mesh material $\left(c=2.1 \times 10^{4}\right.$ dynes $\left./ \mathrm{cm}^{2}\right)$ the values are 29 and 18 .

From texts (Ref. 7) theoretical values of $N_{c}$ and $N_{Y}$ can be obtained as functions of the angle of internal friction of the soil, so that the right side of $\mathrm{Eq}_{\text {(5) and (6) can }}$ be plotted versus the angle of internal friction. For a given test the left side of the equation can be evaluated, and from the literature data a value obtained for the angle of friction. In this way it was found that, in a penetration test, the angle of friction of densely packed -35 mesh samples varies from $45 \mathrm{deg}$ to $47 \mathrm{deg}$. At $45 \mathrm{deg}$ the theoretical values of $N_{c}$ and $N_{\gamma}$ for a circular footing are 175 and 220 respectively, so that it can be seen from $\mathrm{Eq}(5)$ that the very small cohesion $\left(1.4 \times 10^{4}\right.$ dynes $\left./ \mathrm{cm}^{2}\right)$ of this material accounts for about $92 \%$ of the bearing capacity for the small probe and $88 \%$ for the larger probe.

Similarly the angle of friction of the densely packed $-100+150$ mesh sample was found to be about $36 \mathrm{deg}$. At this value $N_{c}$ and $N_{Y}$ for a circular probe are 65 and 32 respectively so that the cohesional term provides about $98 \%$ of the bearing capacity.

All of these calculations were carried out on the basis that the cohesion of the sample at the point of applica- tion in the penetration tests was the same as that indicated by the direct shear test. This is inexact, since the cohesion would in practice probably vary with the atmospheric humidity and from place to place within the test sample. It can be seen from an examination of the factor $c / p g R$ and $\mathrm{Eq}(5)$ that a change as small as $5 \times 10^{3}$ dynes $/ \mathrm{cm}^{2}$ in the value of $c$ affects this factor markedly and thereby also affects the calculated angle of friction and the relative contributions of the $N_{c}$ and $N_{\gamma}$ terms. Changes of the amount indicated in $c$ would be very hard to measure.

In the tests on the loosely packed samples, the bearing capacity was defined as the load per unit area when the probe had penetrated to a depth equal to the diameter of the probe. Although the two modes of failure differ, it is convenient to employ $\mathrm{Eq}_{\mathrm{q}}(1)$ to give

$$
p=\frac{P}{\pi R^{2}}=c N_{e}+\gamma R\left(2 N_{q}+N_{\gamma}\right)
$$

Experimental work in soil mechanics has indicated that for a circular footing $N_{q}$ is approximately $1 / 2 N_{\gamma}$ so that $\mathrm{Eq}_{\mathrm{q}}(7)$ can be reduced to

$$
p=c N_{c}+2 \rho g R N_{\gamma}
$$

or

$$
p_{m}=\frac{c N_{c}}{g}+2_{\rho} R N_{\gamma}
$$

Since the cohesion in the loosely packed material is considered to be negligible, Eq (8) and (9) can be simplified to

$$
\begin{gathered}
p=2_{\rho g R N_{\gamma}} \\
p_{m}=2_{\rho} R N_{\gamma}
\end{gathered}
$$

It should be noted from $\mathrm{Eq}(4)$ and (11) that the bearing capacity should increase with an increase in the radius or more generally with the smaller dimension of the contract area. For the loosely packed material the bearing capacity is directly proportional to the radius. For the densely packed material the change would be smaller, because of the large contribution attributed to cohesion, which is independent of probe size. On this basis, the range of bearing capacities observed for all samples in vacuum with the small probes would correspond to bearing capacities of 1.3 to $7.0 \mathrm{~kg} / \mathrm{cm}^{2}$ on a contact area of $10 \mathrm{~cm}$ radius. 
The effect of a difference in gravitational field on the static bearing capacity can be examined by reference to $\mathrm{Eq}(4)$ and (11). In a loosely packed sample (negligible cohesion) the mass bearing capacity $\left(\mathrm{kg} / \mathrm{cm}^{2}\right)$ would be the same in any gravitational field, since $g$ does not appear in $\mathrm{Eq}(11)$. The stress supported (dyne/ $\mathrm{cm}^{2}$ or $\mathrm{lb} / \mathrm{ft}^{2}$ ) would be directly proportional to the gravitational field (Eq 10). In a densely packed sample, the cohesion contributes a major portion to the bearing capacity, and since in $\mathrm{Eq}(4)$ the cohesion term increases with a decrease in $\mathrm{g}$, the mass bearing capacity would also increase at lower values of gravity.

It would be predicted that effects of atmosphere upon static bearing strength for material of a given internal structure would arise only from the effect of reduced pressure upon the adhesion and the surface friction coefficient of the individual grains, and thereby on cohesion and the gross friction angle of the material. (In dynamic tests, forces associated with movement of air through the pores of the soil also play a role.) Since no differences in static bearing behavior in air and vacuum were observed, the surface adhesion and friction of the individual grains was probably not much different as a result of the relatively short exposure to $10^{-11} \mathrm{~mm} \mathrm{Hg}$ than they were at 1 atm. The pressure on the Moon's surface is much lower than that used in this series of tests, and the surface of lunar rock particles would be freer of absorbed gases. This would tend to raise the friction and adhesive between particles and as a consequence the bearing capacity. It is also possible that some sintering of the lunar dust occurs over the years.

In applying the results of the present work, perhaps the most important finding is that vacuum, at least to the levels studied, appears to have little effect on soil bearing capacity and that the bearing capacity of a given soil in vacuum is certainly at least as high as in air. (The effect of a small amount of cohesion on the bearing capacity as measured by small probes is also of interest.) Thus it would appear, without detailed knowledge of lunar soil structure, that static footing or traction element designs can be based upon tests of the hypothetical soil in air. The state of packing of the soil is the major factor in determining its mechanical properties. It is extremely difficult to maintain very low packing densities on dry rock powders under terrestrial conditions of mineral friction and adhesion. Even the slightest vibration or other disturbance induces an increase in packing density and therefore a major increase in bearing capacity. The lunar surface is subject to meteoroid bombardment, severe thermal fluctuations, and possibly some seismic disturbances. It seems most unlikely, then, that rock powders comprising contacts between the particles without adhesion could remain at extremely low densities corresponding to degrees of packing as low or lower than some employed in the present work. If adhesion is present it is possible that very low density granular materials could exist on the lunar surface in spite of vibration disturbances; the adhesion would increase their strength. 


\section{CONCLUSIONS}

On the basis of the work described, the following conclusions were reached.

1. The static load bearing capacity of rock powder is the same after a short period in a vacuum of $10^{-6} \mathrm{~mm} \mathrm{Hg}$ as it is in air.

2. The bearing capacity is dependent principally on the state of packing of the material.

3 . In vacuum the lowest mass bearing capacity, measured with a probe of $1.43 \mathrm{~cm}$ radius, was $0.17 \mathrm{~kg} / \mathrm{cm}^{2}$ for a very loosely packed sample. For a very densely packed sample the highest mass bearing capacity was about $7 \mathrm{~kg} / \mathrm{cm}^{2}$; because of the small probe size $(0.45 \mathrm{~cm}$ radius) this capacity arose primarily from a small amount of cohesion. The corresponding bearing capacities on a contact area of $10 \mathrm{~cm}$ radius, as calculated from these measurements, would be approximately 1.3 and $7.0 \mathrm{~kg} / \mathrm{cm}^{2}$.

4. Small amounts of cohesion may make an important contribution to soil bearing capacities measured with small probes.

5. For a given loosely packed sample the mass per unit area which can be sustained should be the same in the Moon's gravitational field as in that of the Earth. The stress that can be sustained should be $1 / 3$ as great. When cohesion is present in a densely packed sample, the mass per unit area which can be sustained should be greater in the Moon's gravitational field than on the Earth.

\section{REFERENCES}

1. Kopal, Z., Physics and Astronomy of the Moon, New York, Academic Press, New York, 1962.

2. Roddy, D. J., J. B. Rittenhouse, and R. F. Scott, "Dynamic Penetration Studies in Crushed Rock Under Atmospheric and Vacuum Conditions," AlAA Journal Vol. 1, 1963 pp. 868-873. (Also Jet Propulsion Laboratory Technical Report No. 32-242.)

3. Geer, R. L., "Impact Studies on Lunar Dust Models at Various Vacuums," U.S.A.F., ASD, TR 61-595 (1961).

4. Bernett, E. C., L. D. Jaffe, H. E. Martens, and H. L. Wood, "Thermal Properties of a Simulated Lunar Material in Air and in Vacuum," Jet Propulsion Laboratory Technical Report No. 32-368.

5. Halaiian, J. D., "Laboratory Investigation of Moon Soils," Institute of Aerospace Sciences Paper 62-123 (1962).

6. Spencer, M. E., "Relationship Between Porosity and Angle of Internal Friction," Proc. 5th International Conf. on Soil Mechanics and Foundation Engineering, 3, p. $139(1961)$.

7. Terzaghi, K., Theoretical Soil Mechanics, New York, Wiley, 1943, p. 125. 